\title{
Exophthalmos in the Guillain-Barré syndrome. An unusual presentation
}

\author{
GRAHAME BoDdIE \\ M.B., M.R.C.P.
}

\author{
Michael A. SAmbrook \\ M.D., M.R.C.P.
}

PeTER D. MOHR

B.Sc., M.B., M.R.C.P.

University Department of Neurology, The Royal Infirmary, Manchester

\begin{abstract}
Summary
Papilloedema, multiple cranial nerve palsies, and autonomic nervous system dysfunction have become increasingly well recognized as occurring in the Guillain-Barré syndrome. Such a patient was recently encountered in whom the additional presenting feature of severe bilateral exophthalmos led to delay in reaching the correct diagnosis. Because of this delay and ensuing respiratory complications, permanent visual failure secondary to papilloedema occurred.
\end{abstract}

\section{Case report}

A 32-year-old labourer was transferred to the Royal Infirmary, Manchester, with a 2-week history of exertional dyspnoea, bilateral pleuritic chest pain, general malaise and rigors. During the same period he had noticed rapidly progressive muscle weakness so that he was unable to sit or stand unaided. For 1 week he had noticed protuberance and swelling of the eyes associated with diplopia. He had also during the past 3 weeks had one episode of haemoptysis, occasional vomiting, and numbness in the left hand. He smoked forty cigarettes a day and had noted episodic hoarseness of his voice during the past 6 months.

General examination showed an obese, ill man with plethoric facies who was sweating profusely. The temperature was $38.4^{\circ} \mathrm{C}$, the pulse 120 and respiration 24 . The blood pressure was $195 / 140$ mmHg. Neurological examination showed severe bilateral papilloedema with haemorrhages and exudates; striking bilateral exophthalmos (Fig. 1) with a partial external ophthalmoplegia, involving movements in all directions of gaze especially upwards; and bilateral lower motor neurone facial weakness. Other cranial nerves including visual fields and visual acuity were normal. In the limbs, there was global muscle weakness, most marked proximally in the upper limbs. Reflexes were absent and plantar responses unreactive. There were no sensory abnormalities.

Correspondence: Dr P. D. Mohr, Department of Neurology, Manchester Royal Infirmary, Oxford Road, Manchester M13 9WL.

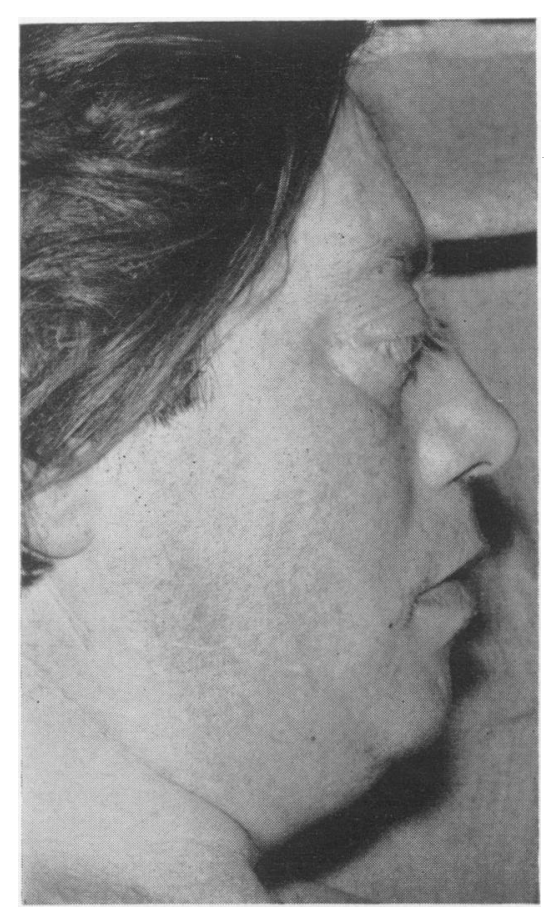

FIG. 1. Profile of patient showing exophthalmos.

\section{Investigations}

(a) Initial

The haemoglobin was $18 \cdot 1 \mathrm{~g} \%$, white cell count 15,900 with $87 \%$ neutrophils and the ESR $81 \mathrm{~mm}$ in the first hour (Westergren). The urea nitrogen was $48 \mathrm{mg}$ with normal electrolytes and blood gases, and the protein $7 \cdot 3 \mathrm{~g}$ (the albumin $3.2 \mathrm{~g}$ and the globulin $4 \cdot 1 \mathrm{~g})$. Electrophoresis showed increased $\alpha^{2}$ and gamma globulin fractions. Chest film showed patchy inflammatory changes throughout both lung fields. Heart size was normal. Electrocardiogram showed a sinus tachycardia.

\section{(b) Subsequent}

Serum calcium, phosphate, alkaline phosphatase, LE cells, antinuclear factor, blood cultures, urina- 
lysis, toxoplasma dye test, thyroid function tests (including TRH-TSH test, thyroid antibodies, and serum TSH, $\mathrm{T}_{3}$ and $\mathrm{T}_{4}$ levels) were normal. Urinary porphyrins were negative and 24-hr urinary levels of normatadrenaline and 17 ketosteroids/ketogenic steroids, normal. No urinary myoglobin was detected. Skull film and computerized axial tomography scan were normal. Muscle enzymes were mildly elevated-SGOT $96 \mathrm{u}$ and creatinine phosphokinase $95 \mathrm{u}$. A muscle biopsy showed occasional necrotic fibres without any cellular response and with normal blood vessels. Electromyography (EMG) showed widespread denervation changes with normal motor and sensory nerve conduction velocities.

\section{Clinical progress}

The initial diagnosis was of an acute neuromyopathy with endocrine dysfunction probably secondary to an underlying carcinoma. Owing to this and the severe papilloedema, lumbar puncture was not done at this stage. The hypertension was treated with hydralazine and settled within 10 days. Despite treating the bronchopneumonia with ampicillin and physiotherapy, the patient continued to deteriorate, became semi-comatose and required ventilation. A pulmonary abscess subsequently developed which required thoracotomy and drainage. Klebsiella aerogenes was isolated, sensitive to gentamicin. During this critical period of 2 weeks the patient was comatose. Over the next 6 weeks the patient's conscious level, respiratory state, muscle power and ophthalmoplegia improved and the papilloedema resolved with the development of consecutive optic atrophy. There was no change in the degree of exophthalmos. On retesting visual acuity, it became apparent that the patient was blind.

At this time, owing to a combination of factors (marked improvement, failure to find an underlying carcinoma, persisting areflexia and the development of distal wasting), the diagnosis of the GuillainBarré syndrome was considered. Cerebrospinal fluid examination showed a protein of $260 \mathrm{mg} \%$ with 1 white cell. Repeat EMG studies showed more marked denervation changes but nerve conduction velocities were still within normal limits.

The patient continued to improve and was discharged home 5 months after admission. The degree of exophthalmos was unchanged.

\section{Discussion}

The clinical features in this patient were compatible with a diagnosis of the Guillain-Barré syndrome, apart from the severe exophthalmos the presence of which led to a delay in reaching the correct diagnosis. Only one other case is recorded of the Guillain-Barré syndrome in which exophthalmos has been reported (Taylor and McDonald, 1932). ఏ Although Drachman (1968) has described exophthal- $\frac{\pi}{\infty}$ mos in chronic hypertrophic polyneuropathy due to $\varrho$ hypertrophied nerves within the orbit, such $a \stackrel{c}{\complement}$ mechanism cannot be implicated in the present case. $\overrightarrow{\vec{F}}$ Other factors such as raised intracranial pressure and $\frac{\overrightarrow{0}}{0}$ ophthalmoparesis may play a part in the patho- $\frac{C}{\partial}$ genesis of the exophthalmos but their consideration $\frac{\bar{\sigma}}{\bar{s}}$ is purely speculative.

There seems little doubt that the delay in diagnosis $\cong$ and the respiratory complications were responsible $\tilde{\Phi}$ for the occurrence of permanent visual failure conse- $\overrightarrow{0}$ quent to severe papilloedema. Papilloedema occurs $\vec{\overrightarrow{ }}$ in about $2-3 \%$ of patients with the Guillain-Barré syndrome (Charbounel, Fève and Blineau, 1970) and rare cases of consecutive optic atrophy have been $\frac{3}{3}$ reported by Feldman, Landau and Halpern (1955), ir Riser et al. (1957) and Martin (1961). The rare association of optic neuritis with the Guillain-Barré syndrome has been reported by Wlodarczyck (1949), i Saracco, Genevet and Mouly (1971) and Nikoske- $\stackrel{\oplus}{\omega}$ laineu and Riettinen (1972), the degree of visual 음 impairment in these patients was mild although $\rightarrow$ Moureu, Vital-Bérard and Poinso (1971) have $\bar{z}$ reported severe visual failure in a patient with bilateral retrobulbar neuritis associated with the $\vec{\varphi}$ Guillain-Barré syndrome.

It should be recognized that exophthalmos mas be a presenting feature of the Guillain-Barre sys drome, and that, although rare, papilloedema, in adequately treated, can result in permanent visual failure.

\section{Acknowledgments}

We are indebted to Dr G. M. Colson who referred the patient and to Dr L. A. Liversedge and Dr R. G. Lascelles for helpful criticism.

\section{References}

Charbounel, A., Fìve, J.R. \& Blineau, M.F. (1970) Les signes oculaires des polyradiculonévrites aiguës inflammatoires. Cahiers de Médecine, 11, 505.

Drachman, D.A. (1968) Ophthalmoplegia plus. The neuro- 옥 degenerative disorders associated with progressive external ophthalmoplegia. Archives of Neurology, 18, 654.

Feldman, S., Landau, J. \& HalPern, L. (1955) Papilloedema in the Guillain-Barré syndrome. Archives of Neurology and Psychiatry, 73, 678.

MaRTIN, J.J. (1961) Polyradiculonévrite avec dissociation albuminocytologique du type Guillain-Barré et atteinte $\omega$ optique. Considération anatomo-clinique. Psychiatria et neurologia. Basel, 142, 265.

Moureu, P., Vital-Bérard, P. \& Poinso, Y. (1971) Névrite optique rétrobulbaire au cours d'un syndrôme de Guillain- \& Barré. Revue d'oto-neuro-ophtalmologie, 43, 216.

Nikoskelaineu, E. \& Riettinen, P. (1972) Retrobulbar neuritis as an early symptom of Guillain-Barré syndrome : report of a case. Acta ophthalmologica, 50, 111. 
Riser, M., Géraud, J., Rascol, X., Riser, A. \& SaintMARC, M. (1957) Syndrôme de Guillain-Barré et Strohl à évolution ascendante avec hypertension intra-crânienne. Bulletin et Mémoires de la Société médicale des Hôpitaux de Paris, 73, 689.

Saracco, J.B., Genevet, J. \& Mouly, A. (1971) Atrophie optique et dissociation albumino-cytologique. Bulletin des sociétés d'ophtalmologie de France, 71, 637.
TAYlor, E.W. \& McDonald, C.A. (1932) The syndrome of polyneuritis with facial diplegia. Archives of Neurology and Psychiatry, 27, 79.

WloDARCZYCK, S. (1949) Un cas de syndrôme de GuillainBarré avec névrite optique rétrobulbaire. Neurologia, neurochirurgia; psychiatria polska, 23, 110.

\title{
Osteomalacia associated with increased renal tubular resorption of phosphate (hypohyperparathyroidism)
}

\author{
J. A. Kanis \\ B.Sc., M.B., Ch.B., M.R.C.P. \\ R. J. WALTON \\ B.Sc., M.B., B.S., M.R.C.P. \\ Metabolic Units, Western General Hospital, Edinburgh, and Nuffield Orthopaedic Centre, Oxford
}

\section{Summary}

A 12-year-old girl, who presented with joint pains, was found to have hypocalcaemia, hyperphosphataemia due to increased renal tubular reabsorption, increased serum alkaline phosphatase activity, and osteomalacia. These features, which resemble those found in socalled hypohyperparathyroidism, were all rapidly reversed by small doses of cholecalciferol.

\section{Introduction}

Costello and Dent (1963) suggested the term hypohyperparathyroidism to describe the apparent co-existence of parathyroid overactivity and diminished renal responsiveness to parathyroid hormone (PTH) in a seven-year-old girl with normal glomerular function and with no stigmata of pseudohypoparathyroidism. Biochemical hypoparathyroidism was inferred from the low serum calcium (Ca) and high serum inorganic phosphate (Pi), whilst typical $X$-ray changes and increased activity of serum alkaline phosphatase (SAP) suggested parathyroid overactivity. Allen, Millard and Nassim (1968) reported increased osteoid in a bone biopsy specimen from a similar patient. Recently, a twelveyear-old girl with similar features has been studied, and her response to cholecalciferol is reported.

\section{Case report}

A 12-year-old female Indian immigrant, who had lived in Scotland for the previous 4 years, presented in April 1973 with a 4-week history of pain

Correspondence: Dr J. A. Kanis, Nuffield Orthopaedic Centre, Headington, Oxford OX3 7LD. in the knees. She had previously been in good health and her menstrual periods had just begun. She was of normal height $(150 \mathrm{~cm})$ and weight $(40 \mathrm{~kg})$, and secondary sex characteristics were present. Chvostek's sign was present but there were no other abnormal features on examination.

Results of investigations were as follows: chromosomal karyotype was that of a normal female; serum $\mathrm{Ca}$ was low and plasma Pi was increased (Table 1); SAP activity was 427 iv/l, which is markedly elevated for a girl of this age (Clark and Beck, 1950; Round, 1973), and qualitative electrophoresis showed that this increased activity was of bony origin; plasma urea, creatinine, magnesium and other electrolytes were normal; there was no amino-aciduria, glycosuria or proteinuria; the urinary excretion rate of calcium was very low, $0.7 \mathrm{mEq} / 24 \mathrm{hr}$; the estimated maximum renal tubular resorption of phosphate per unit of glomerular filtration rate $\left(\mathrm{Tm}_{\mathrm{P}} / \mathrm{GFR}\right)$ (Bijvoet and Morgan, 1971) was markedly elevated (Table 1); urine acidity after oral ammonium

TABLE 1. Investigations before and during treatment with cholecalciferol

\begin{tabular}{lccc}
\hline & $\begin{array}{c}\text { Before } \\
\text { treatment }\end{array}$ & $\begin{array}{c}\text { After 6 } \\
\text { weeks of } \\
\text { treatment }\end{array}$ & $\begin{array}{c}\text { Normal } \\
\text { adult } \\
\text { range }\end{array}$ \\
\hline Serum Ca (mEq/1) & $3 \cdot 4$ & $4 \cdot 5$ & $4 \cdot 5-5 \cdot 0$ \\
Plasma Pi (mg/100 ml) & $6 \cdot 0$ & $4 \cdot 9$ & $2 \cdot 7-4 \cdot 5$ \\
SAP (iu/l) & 355 & 210 & $25-85$ \\
Serum 25-OHD (ng/ml) & $<0 \cdot 8$ & 25 & $4-23$ \\
Serum PTH (ng/ml) & $2 \cdot 0$ & $<0.9$ & $<0 \cdot 9$ \\
TmP/GFR (mg/100 ml) & $7 \cdot 4$ & $4 \cdot 2$ & $2 \cdot 5-4 \cdot 2$ \\
\hline
\end{tabular}

